\title{
Evaluation of goat body lipids change according to the level of feeding by the condition scoring method
}

\author{
M Cissé, I Ly, R Manga \\ Institut Sénégalais de Recherches agricoles, BP 2057, Dakar, Senegal
}

In the Sahelian tropics, a high seasonality characterized the natural feed resources availability. There is forage abundance during the rainy season ( $3 / 12$ months) and scarcity in the dry season. Therefore, cyclic phases in body reserves change, with regard to animal nutritional status, can be expected. Among numerous methods available for body composition estimation in field, body condition scoring is the more practical and the less onerous. It allows to define objective scores during production cycles and facilitates the establishment of feeding programs. At the present time, it was introduced in most of our research programs in livestock production systems. In a previous work, the scoring method was calibrated in the Sahel goat (Cissé et al, 1992, In Proc Biennal Conf Small Rum Net, Arusha, Tanzania), a local dairy breed reared on extensive pasture. This study aimed at determining in this goat the monthly change in body weight (BW) and in BCS and to evaluate the effect of supplementation on these parameters.

Fifty female Sahel goats, two years old and $24.7 \mathrm{~kg} \mathrm{BW}$ on average, were used in this work. Goats were managed on pasture of the periurban zone with 8 males, and given a low level of supplementation $(300 \mathrm{~g}$ of groundnut cake/animal/day) during the last three months of the dry season (from April to June). During one year, they were monthly weighed and their body condition scored using a scale of $6(0-5)$ points instead of 5 (1-5) points, as in Santucci et al (1991, Goat Nutrition, Pudoc publ, Netherlands, pp 240-255), because of extremely poor conditions seen in local goat. Activities of animals on pasture and feed behaviour in terms of herbaceous and ligneous forage contribution in the diet were also studied as in Guérin et al (1988, Rev Elev Méd Pays trop, 41, 427-440).

Through the year, the BW increased and seasonal differences were observed in the mean daily gain ( $165 \pm 22 \mathrm{~g} / \mathrm{d}$ in September vs $54 \pm 15 \mathrm{~g} / \mathrm{d}$ in April) in all goats, without taking into account their physiological state. BW and BCS profiles were almost parallel, except at the end of the dry season, from May to June. At this critical period, goats significantly lost BCS $(-0.59 \pm 0.35$ point, $P<0.05)$, while their BW remained constant $(0.5 \pm 0.7 \mathrm{~kg})$. The number of normal kiddings observed in the herd was 22 and the optimum score of the goat at mating seems to be $3.2 \pm 0.5$ points. Goats were in best condition ( $4.2 \pm 0.6$ points) during September, where contribution of herbaceous forage in the diet peaked $(95 \%)$. This can be correlated to the excellent nutritive value of herbaceous at this period (Guérin et al, 1988). After September, ligneous plants portion in the diet increased progressively and, owing to their high nitrogen content, allowed to goat to be in better condition than beefs and sheep in this area. However the level of ligneous forage intake was not sufficient to maintain goat condition during shortage. Furthermore, their large movings to find feeds increases energy expenditure and adds to the deficit, at this period. Using the equation between BCS and the total adipose tissue weight and the lipid content (Cissé et al, 1994, In Proc Soc Nutr Physiol, Willingen, Germany, 25-30), an approximate decrease of $440 \mathrm{~g}$ in fat deposits and in $0.6 \mathrm{~kg}$ in body lipid content could be expected in these goats, at the critical period of the dry season. This study showed that the level of supplementation applied was not sufficient to prevent a loss in goat body condition, at the end of the dry season. 